\title{
CAVITATION RESISTANT LAYERS FROM STELLITE ALLOY DEPOSITED BY TIG WELDING ON DUPLEX STAINLESS STEEL
}

\author{
Daniel MUTAŞCU, Ion MITELEA, Ilare BORDEAŞU, \\ Dragoş BUZDUGAN, Florin FRANT \\ University Politehnica Timişoara, Timişoara, Romania, EU \\ daniel.mutascu@upt.ro, ion.mitelea@upt.ro, ilare.bordeasu@upt.ro, dragos.buzdugan@upt.ro \\ florin.frant@upt.ro
}

https://doi.org/10.37904/metal.2019.834

\begin{abstract}
The cobalt based alloy, Stellite, was deposited through the TIG welding process on the surface of a Duplex stainless steel to improve cavitation erosion resistance of engineering components that work in aggressive environments. Cavitation tests were performed using ultrasonic vibratory equipment which complies with requirements of the ASTM G32 - 2010 standard. The microstructure of the deposited layers consisted of complex carbides in a Co-Cr solid solution strengthened alloyed matrix with a dendritic structure which ensures high hardness and a significant increase in cavitation erosion resistance compared to the base metal.
\end{abstract}

Keywords: Alloy Stellite, welding, cavitation, microstructure

\section{INTRODUCTION}

The Duplex stainless steels combine the favorable properties of the two constitutive phases (ferrite and austenite), being considered as high-performance materials for mechanical stress and corrosion under stress in chlorine ion environments [1]. As a result of these properties, these alloys are selected for applications in the chemical and petrochemical industries, food industry, marine oil and gas drilling platforms, seawater desalination equipment, etc. In addition, the nickel high cost has been the reason for selecting these alloys (with lower content in this alloying element) for new applications where they have become competitive.

Cavitation erosion resistance is an extremely important feature for many systems in the industries mentioned above. A number of research papers [2], have shown that due to the presence of ferrite and the interfaces between the two constitutive phases $(\alpha / \gamma)$, these alloys have a significantly less cavitation resistance than other stainless steels.

To improve this surface characteristic, depositing suitable alloys with high hardness and high ductility is essential. Stellite type alloys are recommended to be used for parts under heavy loads like valves, shafts and other parts of the automotive, aerospace, oil and gas industry, metallurgy, power generation equipment, etc. They are delivered as rods, wires, powders and electrodes.

This paper aims to investigate the role of Stellite alloy deposited layers through TIG welding process on Duplex stainless steel to prevent the surface of the parts from degradation by cavitation erosion.

\section{EXPERIMENTAL PROCEDURE}

The material selected for the substrate is X2CrNiMoN22-5-3 Duplex Stainless Steel subjected to annealing solution by heating to $1060^{\circ} \mathrm{C}$ followed by rapid cooling in water. On the front surface of the set of 3 samples to be subjected to the cavitation test (Figure 1) were deposited by TIG welding 1,2 and 3 layers of a Stellite alloy wire having a diameter of $3.2 \mathrm{~mm}$. Following the deposits made, for each sample was prepared a smooth surface by grinding - polishing operations. 


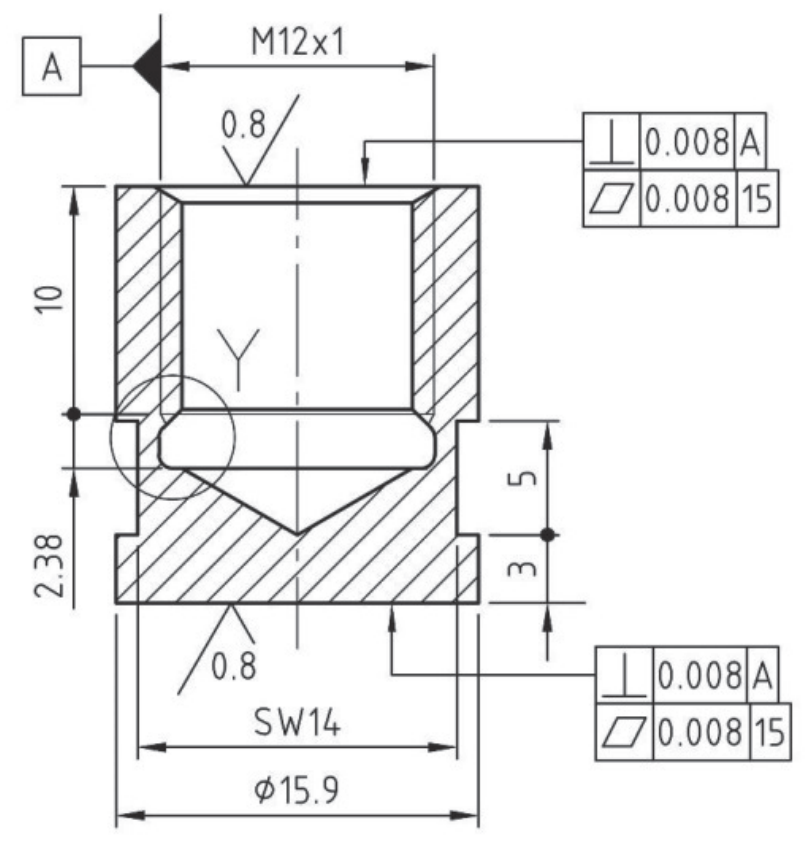

Figure 1 Cavitation sample

The cavitation tests were performed on a vibrator with piezoceramic crystals, which complies with the ASTM G32 - 2010 standard requirements (see the main diagram of Figure 2) [2]. The functional parameters that determine the cavitation erosion intensity are: the double vibration amplitude of $50 \mu \mathrm{m}$, the frequency of 20000 $\pm 2 \% \mathrm{~Hz}$ and the cavitation liquid temperature (double distilled water) of $22 \pm 1{ }^{\circ} \mathrm{C}$. To determine the wear rate through cavitation erosion, the test was discontinued at regular intervals the samples were washed in acetone, dried in a hot air stream and weighed with an analytical scale which can weigh the masses with a precision of five decimal places.

Microstructural investigations were conducted on a Leica DM2700M optical microscope and a TESCAN VEGA 3LMU Bruker EDX Quantax electronic microscope.

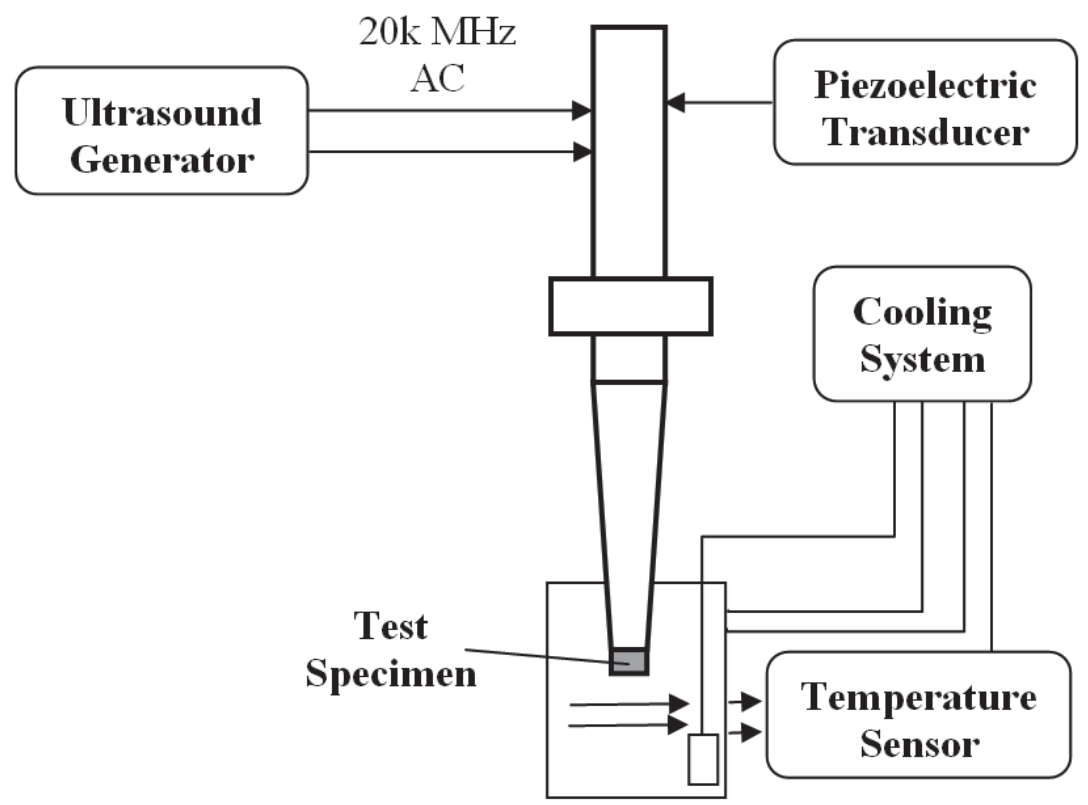

Figure 2 Details about the ultrasonic equipment used in the cavitation erosion experiments 


\section{RESULTS AND DISCUSSIONS}

\subsection{Cavitation curves}

Figures 3 and $\mathbf{4}$ show the variation curves of mass losses and erosion rates as a function of the cavitation attack time for both the base material used as the substrate and the material coated with 1,2 and 3 layers of a Stellite alloy.

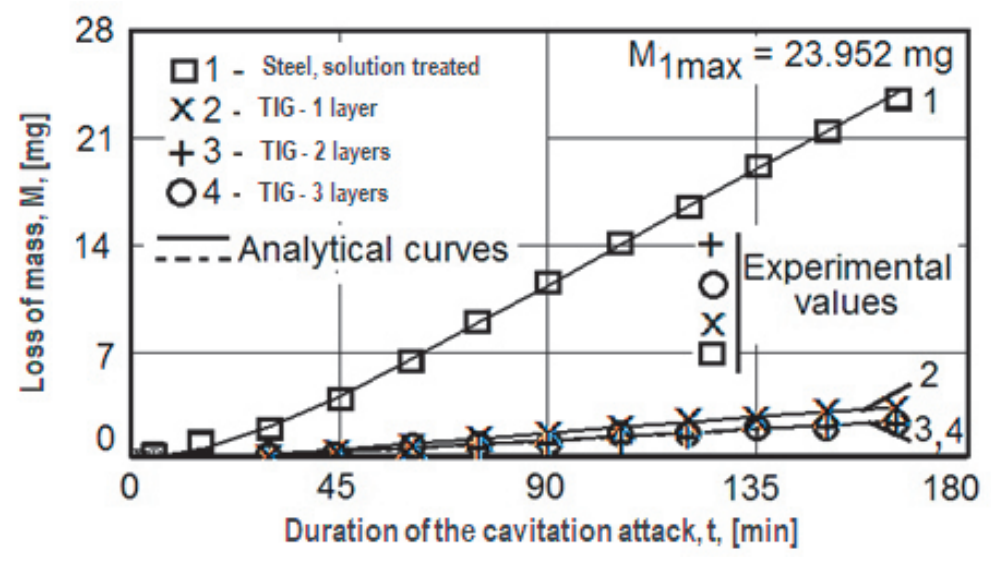

Figure 3 The evolution of mass losses with the duration of the cavitation attack

The following observations can be made after the analysis:

- $\quad$ after $165 \mathrm{~min}$. of the cavitation attack, the loss of mass suffered by the Duplex stainless steel is approx. $24 \mathrm{mg}$ and the cavitation erosion rate is approx. $0.17 \mathrm{mg} . \mathrm{min}$.;

- $\quad$ compared to the base material, the TIG welded layers exhibit a reduction in mass losses of approx. 7 10 times and the erosion speed of $7-11$ times;

- $\quad$ regardless of the number of deposited TIG layers, the cavitation resistance of the Stellite alloy is excellent.

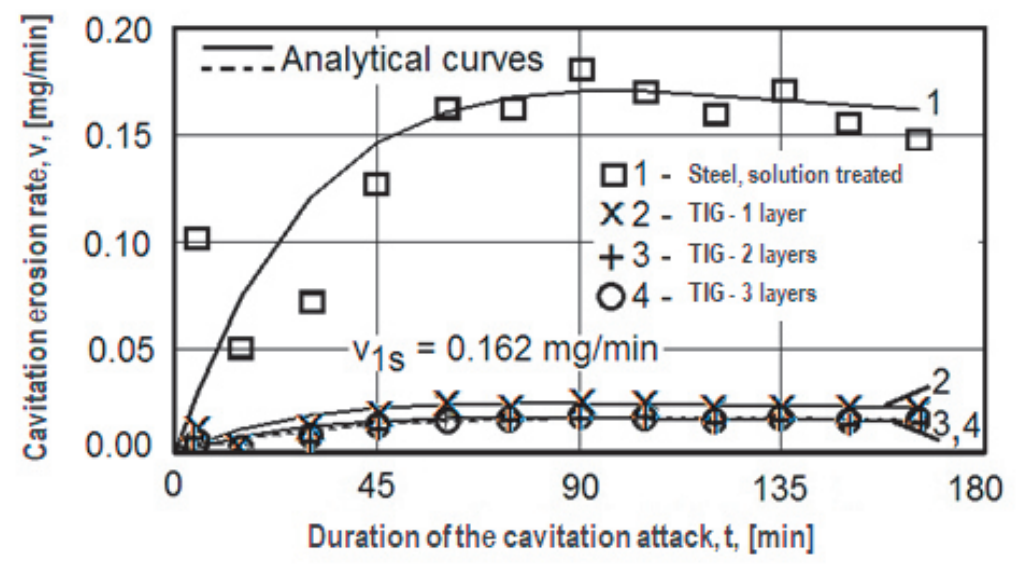

Figure 4 Variation of erosion rate with the duration of the cavitation attack

\subsection{Microstructural analysis}

EDX analysis on coatings (Figure 5) prove that in the chemical composition of the investigated alloy there is $\mathrm{Co}$ as a basic element and other alloying elements such as $\mathrm{Cr}, \mathrm{W}, \mathrm{Fe}, \mathrm{Ni}$ and $\mathrm{C}$. As a result of the dilution phenomenon, the $\mathrm{Fe}$ and $\mathrm{Cr}$ concentrations of the first coating are slightly higher than those of the third coating (Figure 5a compared to Figure 5b). The microstructure of the deposited layers (Figures $\mathbf{6} \mathbf{a}, \mathbf{b}$ ) is made up 
of high hardness complex carbides, dispersed in a hardened $\mathrm{Co}-\mathrm{Cr}$ solid solution matrix having a dendritic structure. Chromium is the element that provides good resistance to corrosion and oxidation, as well as mechanical resistance to high temperatures. It forms hard metal carbides, such as $\mathrm{M}_{7} \mathrm{C}_{3}$ and $\mathrm{M}_{23} \mathrm{C}_{6}$ [3] which improve wear resistance through cavitation erosion. Other alloying elements such as Mo and W favor a further increase in wear resistance by the formation of $\mathrm{MC}$ and $\mathrm{M}_{6} \mathrm{C}$ carbides [3] and intermetallic phases such as $\mathrm{Co}_{3}$ (Mo, W) $[4,5]$.

a)
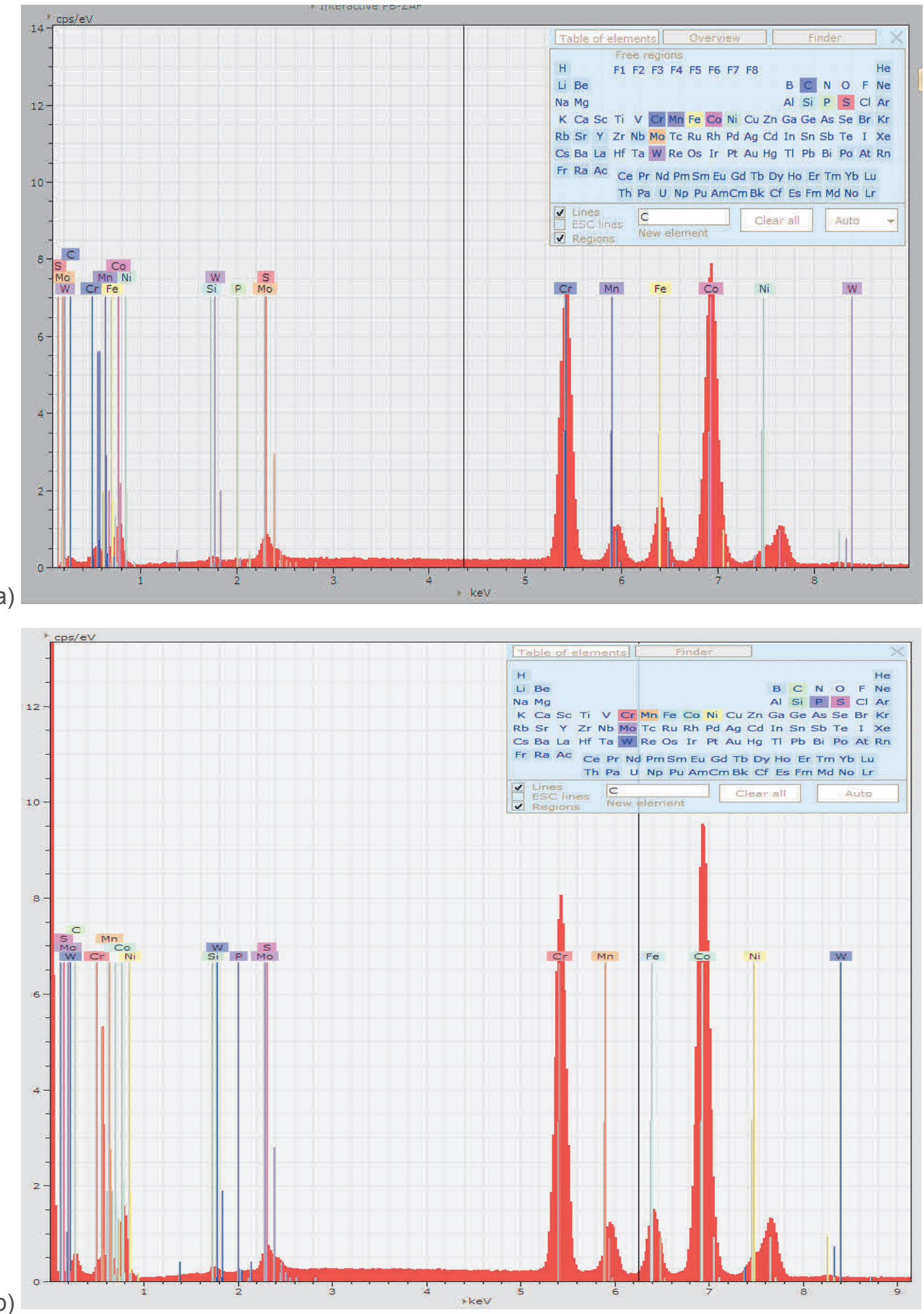

Figure 5 EDX images of Stellite alloy coatings: a - 1 layer deposited; b - 3 layers deposited 


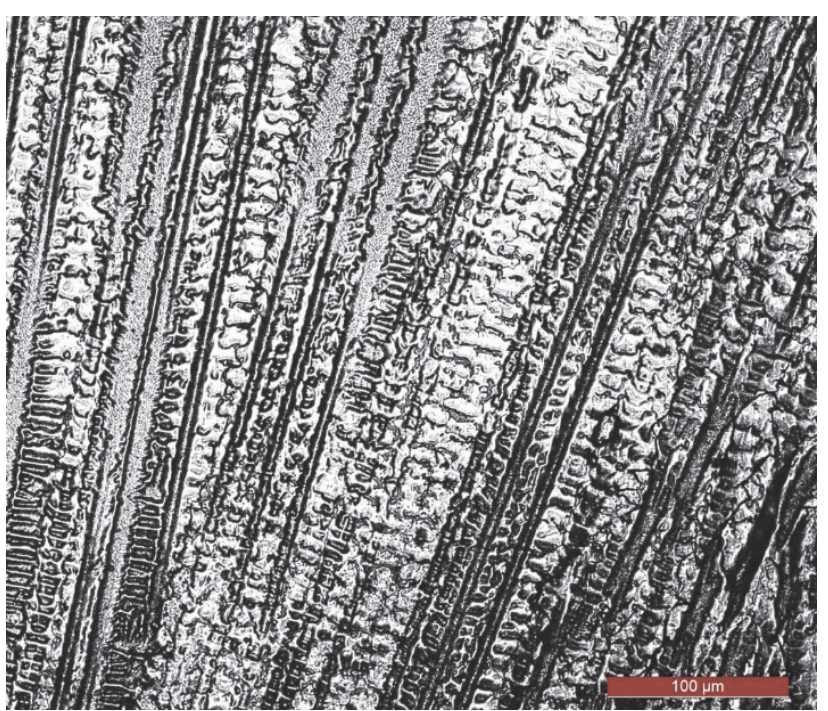

a)

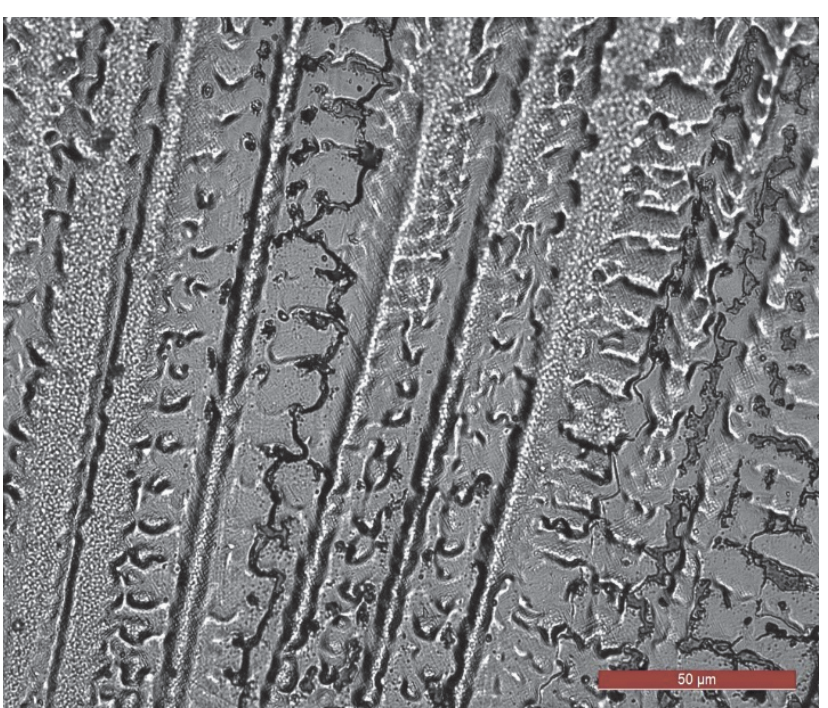

b)

Figure 6 Microstructure of Stellite alloy layers: a - lower magnification; b - double magnification than in case of a)

\section{CONCLUSION}

The deposition through TIG welding of the Stellite alloys delivered as rods with $3.2 \mathrm{~mm}$ diameter onto a Duplex stainless steel substrate, $\mathrm{X} 2 \mathrm{CrNiMoN22-5-3,} \mathrm{provides} \mathrm{a} \mathrm{significant} \mathrm{improvement} \mathrm{in} \mathrm{cavitation} \mathrm{erosion}$ resistance.

Regardless of the number of layers deposited, mass losses are reduced by approx. 7 - 10 times, and the erosion rate decreases by approx. 7 - 11 times.

The explanation of the increase in cavitation resistance is based on the microstructure of the surface, consisting of a complex dendritic solid solution matrix and high hardness complex carbides.

\section{REFERENCES}

[1] ESPITIA, L. and TORO, A. Cavitation resistance, microstructure and surface topography of materials used for hydraulic components. J. Tribology International. 2010, vol.43, pp. 2037 - 2045.

[2] MITELEA, I., MICU, L.M., BORDEASU, I. and CRACIUNESCU, C.M. Cavitation Erosion of Sensitized UNS S31803 Duplex Stainless Steels. JOURNAL OF MATERIALS ENGINEERING AND PERFORMANCE. 2016. vol. 25, no. 5, pp. 1939-1944.

[3] NAVAS, C., CONDE, A., CADENAS, M. and DE DAMBORENEA, J. Tribological properties of laser clad Stellite 6 coatings on steel substrates. J. Surface Engineering. 2006. vol. 22, no. 1, pp. 26-34.

[4] ROSALBINO, F. and SCAVINO, G. Corrosion behaviour assessment of cast and HIPed Stellite 6 alloy in a chloride-containing environment. J. Electrochimica Acta. 2013. vol. 111, pp. 656-662.

[5] APAY, S. and GULENC, B. Wear properties of AISI 1015 steel coated with Stellite 6 by microlaser welding. J. Materials and Corrosion. 2014. vol. 55, pp. 1-8. 